\title{
PENGARUH BUDGETARY GOAL CHARACTERISTICS TERHADAP KINERJA MANAJERIAL DENGAN KECUKUPAN ANGGARAN DAN KOMITMEN ORGANISASI SEBAGAI VARIABEL PEMODERASI PADA UNIVERSITAS NEGERI YOGYAKARTA
}

\author{
Heni Haryanti \\ Akuntansi Universitas Negeri Yogyakarta \\ hennieyyan@gmail.com \\ Mimin Nur Aisyah \\ Staf Pengajar Jurusan Pendidikan Akuntansi Universitas Negeri Yogyakarta
}

\begin{abstract}
Abstrak : Pengaruh Budgetary Goal Characteristics Terhadap Kinerja Manajerial Dengan Kecukupan Anggaran Dan Komitmen Organisasi Sebagai Variabel Pemoderasi Pada Universitas Negeri Yogyakarta. Penelitian ini bertujuan untuk mengetahui: (1) Pengaruh Budgetary Goal Characteristics terhadap Kinerja Manajerial. (2) Kecukupan Anggaran dalam memoderasi pengaruh Budgetary Goal Characteristics terhadap Kinerja Manajerial. (3) Komitmen Organisasi dalam memoderasi pengaruh Budgetary Goal Characteristics terhadap Kinerja Manajerial. (4) Kecukupan Anggaran dan Komitmen Organisasi bersama-sama memoderasi pengaruh Budgetary Goal Characteristics terhadap Kinerja Manajerial. Metode analisis data menggunakan uji prasyarat analisis, regresi linear sederhana dan moderating regression analysis (MRA). Hasil penelitian ini menunjukkan: (1) Budgetary Goal Characteristics berpengaruh positif terhadap Kinerja Manajerial, ditunjukkan oleh nilai koefisien sebesar 0,481, signifikansi 0,000, dan nilai $t_{\text {hitung }} 5,018$. (2) Kecukupan Anggaran memperkuat pengaruh positif Budgetary Goal Characteristics terhadap Kinerja Manajerial. Interaksi dengan variabel pemoderasi menghasilkan nilai koefisien 0,361, signifikansi 0,000, dan nilai thitung 5,177. (3) Komitmen Organisasi tidak memperkuat pengaruh positif Budgetary Goal Characteristics terhadap Kinerja Manajerial. Interaksi variabel pemoderasi mempunyai nilai koefisien 0,063, signifikansi 0,587, dan nilai thitung 0,546. (4) Kecukupan Anggaran dan Komitmen Organisasi bersama-sama memperkuat pengaruh positif Budgetary Goal Characteristics terhadap Kinerja Manajerial. Interaksi dengan variabel pemoderasi menghasilkan nilai koefisien 0,273, signifikansi 0,035, dan nilai $t_{\text {hitung }} 2,151$ serta $\mathrm{F}$ hitung 12,278.
\end{abstract}

Kata kunci: Kinerja Manajerial, Budgetary Goal Characteristics, Kecukupan Anggaran, Komitmen Organisasi.

\begin{abstract}
The Effect Of Budgetary Goal Characteristics On Managerial Performance With Budget Adequacy And Organizational Commitment As Moderating Variable On Yogyakarta State University. The purpose of this study is to determine: (1) The effect of Budgetary Goal Characteristics on Managerial Performance. (2) Budget Adequacy moderates the effect of Budgetary Goal Characteristics on Managerial Performance. (3) Organizational Commitment moderates the effect of Budgetary Goal Characteristics on Managerial Performance.(4) Budget Adequacy and Organizational Commitment simultaneously moderate the effect of Budgetary Goal Characteristics on Managerial Performance. The method of data analysis used were prerequisite test, simple linear regression analysis, and moderating regression analysis. The results show that: (1) Budgetary Goal Characteristics positively effect on Managerial Performance, showed by coefficient value 0,481, significance 0,000, and $t_{\text {counted }} 5,018$. (2) Budget Adequacy strengthen the positive effect of Budgetary Goal Characteristics on Managerial Performance. Interaction with moderating variable showed coefficient value 0,361, significance 0,000, and tcounted 5,177. (3) Organizational Commitment is not able to strengthen the positive effect of Budgetary Goal Characteristics on Managerial Performance. Interaction with moderating variable have coefficient value is 0,063, significance 0,587, and $t_{\text {counted }}$ 0,546. (4) Budget Adequacy and Organizational Commitment simultaneously strengthen the positive effect of Budgetary Goal Characteristics on Managerial Performance. Interaction with moderating variable showed coefficient value is 0,273, significance 0,035, $t_{\text {counted }} 2,151$, and $F_{\text {counted }} 12,278$.
\end{abstract}




\section{JURNAL NOMINAL / VOLUME V NOMOR 1 / TAHUN 2016}

Key words: Managerial Performance, Budgetary Goal Characteristics, Budget Adequacy and Organizational Commitment.

\section{PENDAHULUAN}

Perubahan yang dinamis dan cepat dalam era globalisasi membawa dampak besar bagi dunia pendidikan khususnya Perguruan Tinggi (PT). Setiap Perguruan Tinggi dituntut untuk dapat menjalankan organisasinya secara efektif dan efesien agar mampu mengikuti perkembangan dalam dunia pendidikan. Perguruan Tinggi merupakan suatu lembaga formal yang mengemban fungsi meningkatkan mutu dan kualitas sumber daya manusia melalui lembaga pendidikan. Perguruan Tinggi merupakan lembaga nirlaba yang harus selalu meningkatkan keunggulan bersaing dan terus memperbaiki kinerja manajamen.

Keberhasilan Perguruan Tinggi dalam menjalankan fungsinya dapat dilihat berdasarkan kinerja yang dicapai. Pencapaian kinerja yang baik dapat diwujudkan dengan melakukan penyesuaian yang tepat dalam menyusun strategi untuk mempersiapkan lulusan yang siap pakai dan mampu bersaing dalam dunia yang kompetitif ini. Strategi yang ditetapkan oleh Perguruan Tinggi harus direncanakan dan dirancang secara matang sesuai dengan visi dan misi yang ingin dicapai

Perguruan Tinggi perlu meningkatkan kinerjanya dalam segala bidang termasuk Kinerja Manajerial. Kinerja Manajerial adalah kecakapan manajer dalam menjalankan fungsi manajemen yang meliputi perencanaan, pengorganisasian, pengarahan, dan pengawasan. Salah satu Perguruan Tinggi Negeri yang perlu meningkatkan Kinerja Manajerialnya agar mampu mempertahankan keunggulan bersaing adalah Universitas Negeri Yogyakarta. Mulai tahun 2008 Universitas Negeri Yogyakarta telah siap menuju World Class University, hal tersebut dilakukan untuk menghadapi adanya tantangan global. Pengakuan internasional berupa sertifikasi terhadap kegiatan manajemen telah berhasil didapatkan yaitu Standar Manajemen Mutu (SMM) International Organization for Standardization (ISO) 9001:2000. Dengan diperolehnya SMM ISO 9001: 2000 tersebut Universitas Negeri Yogyakarta semakin dituntut untuk terus meningkatkan kegiatan manajemen salah satunya dengan terus meningkatkan Kinerja Manajerial. Kinerja manajerial Universitas Negeri Yogyakarta akan meningkat apabila manajer mampu merencanakan strategi dengan tepat. Strategi yang telah ditetapkan harus dilaksanakan sesuai dengan proses perencanaan sehingga perlu dilakukan pengorganisasian, pengarahan dan pengawasan terhadap anggota organisasi.

Berdasarkan wawancara yang dilakukan dengan Kepala Bagian Tata Usaha Fakultas Ilmu Sosial yang 


\section{JURNAL NOMINAL / VOLUME V NOMOR 1 / TAHUN 2016}

dilaksanakan pada 14 Januari 2016 menyebutkan bahwa fungsi manajerial belum sepenuhnya terlaksana, terutama fungsi pengorganisasian (organizing), pengarahan (actuating), dan pengawasan (controlling). Salah satu contoh tidak terpenuhinya fungsi tersebut adalah pelaksanaan pengabdian masyarakat. Perencanaan kegiatan pengabdian masyarakat telah disusun dengan baik. Namun dalam beberapa kegiatan pemenuhan ketiga fungsi lainnya tidak dilakukan dengan baik. Ketua panitia pelaksana kegiatan hanya mengorganisasikan anggota dan masyarakat diawal kegiatan. Untuk keberlangsungan kegiatan tidak dilakukan pengarahan atau pendampingan secara berlanjut kepada masyarakat. Hasil implementasi program juga tidak dievaluasi dan diawasi sehingga banyak program yang tidak berjalan sesuai harapan sehingga Kinerja Manajerial tidak optimal.

Pencapaian Kinerja Manajerial yang baik juga dapat dipengaruhi oleh faktorfaktor lain yang terdapat dalam organisasi, salah satunya yaitu anggaran. Anggaran merupakan implementasi dari perencanaan dan pengendalian dalam fungsi manajemen.

Sesuai dengan Peraturan Pemerintah Republik Indonesia No. 17 tahun 2010 tentang Pengelolaan dan Penyelengaraan Pendidikan Tinggi bahwa Perguruan Tinggi harus merumuskan dan menetapkan anggaran pendapatan dan belanja tahunan (www.dikti.go.id). Salah satu fungsi anggaran adalah untuk menilai kinerja para manajer karena anggaran memiliki pengaruh terhadap perilaku manajer.

Keikutsertaan para manajer dalam penyusunan anggaran akan memotivasi manajer tingkat menengah dan manajer tingkat bawah dalam mencapai tujuan organisasi dan meningkatkan Kinerja Manajerial. Namun, jika dalam pelaksanaannya tidak dilakukan pengawasan adanya partisipasi anggaran dapat menimbulkan masalah salah satunya yaitu timbulnya kesenjangan anggaran, dimana manajer sengaja menetapkan standar aggaran terlalu tinggi atau terlalu rendah serta membuat kelonggaran anggaran untuk mempermudah tingkat ketercapaian anggaran.

Berdasarkan laporan tahunan Dies Natalis UNY, tahun 2014 terjadi penurunan serapan anggaran sebesar $1,71 \%$ dari tahun 2013 yaitu dari 93,66\% menjadi 91,95\%. Terjadinya penurunan serapan anggaran tersebut menunjukkan bahwa pelaksanaan anggaran di Universitas Negeri Yogyakarta belum mencapai tingkat optimal. Kinerja Manajerial yang menurun karena pelaksanaan anggaran yang tidak efektif kemungkinan disebabkan karena fungsi lain dalam manajemen tidak berjalan dengan baik. Fungsi tersebut adalah pengorganisasian (organizing) dan 


\section{JURNAL NOMINAL / VOLUME V NOMOR 1 / TAHUN 2016}

pengarahan (actuating). Apabila manajer telah menyusun perencanaan dengan baik, namun jika tidak diikuti dengan keberhasilan dalam menjalankan fungsi lainnya maka Kinerja Manajerial juga tidak akan maksimal.

Pelaksanaan anggaran yang belum efektif juga dapat disebabkan oleh unsur lain dalam anggaran. Suatu anggaran dapat berjalan secara efektif apabila penyusunan dan penerapan anggaran telah memenuhi lima indikator dalam Budgetary Goal Characteristics yang terdiri dari partisipasi anggaran (budgetary participation), kejelasan sasaran anggaran (budget goal clarity), evaluasi anggaran (budgetary evaluation), umpan balik anggaran (budgetary feedback), dan kesulitan sasaran anggaran (budget goal difficulty). Berdasarkan penelitian Kenis (1979) yang dijelaskan oleh Kurnia (2010) disimpulkan bahwa variasi dalam penyusunan anggaran manajer tingkat atas seperti yang direfleksikan dalam Budgetary Goal Characteristics memiliki pengaruh yang signifikan dari manajer tingkat bawah.

Hubungan antara Budgetary Goal Characteristics terhadap Kinerja Manajerial akan semakin kuat atau sebaliknya menjadi semakin lemah dengan adanya faktor lain yang terlibat dalam anggaran dan organisasi yaitu dengan adanya Kecukupan Anggaran dan Komitmen Organisasi. Kecukupan Anggaran merupakan tingkatan dimana seorang merasa bahwa sumber-sumber anggaran memadai untuk memenuhi syaratsyarat dalam bidang pekerjaannya.

Adanya perubahan sistem pembayaran uang kuliah mahasiswa menjadi sistem UKT tunggal yang berlaku mulai tahun ajaran 2013/2014 mengakibatkan terjadinya kekurangan anggaran pada Universitas Negeri Yogyakarta. Jumlah mahasiswa pada grade I dan II dalam penerapan sistem UKT tunggal mencapai 20\% sehingga sumber anggaran yang tersedia tidak mencukupi dan tidak sesuai dengan anggaran. Hal tersebut mengakibatkan beberapa program yang direncanakan terpaksa dihentikan sementara sehingga di tengah periode anggaran dilakukan perubahan terhadap anggaran. Permasalahan tersebut menunjukkan bahwa Kecukupan Anggaran akan berdampak pada pelaksanaan anggaran yang dapat berpengaruh terhadap Kinerja Manajerial.

Faktor lain yang berpengaruh dalam hubungan antara Budgetary Goal Characteristics dengan Kinerja Manajerial yaitu Komitmen Organisasi. Komitmen Organisasi adalah suatu keadaan dimana individu memiliki kepercayaan, keterikatan, serta penerimaan terhadap nilai dan tujuan organisasi sehingga individu tersebut akan mempertahankan keanggotaannya dalam organisasi. Komitmen Organisasi terbangun apabila masing-masing individu mengembangkan tiga sikap atau karakteristik dalam Komitmen Organisasi, 


\section{JURNAL NOMINAL / VOLUME V NOMOR 1 / TAHUN 2016}

yaitu adanya keyakinan, kesediaan untuk terlibat dalam kepentingan organisasi (involvement), dan loyalitas.

Masing-masing individu atau manajer dalam organisasi akan memiliki komitmen yang tinggi apabila mereka bangga dengan organisasi tempat mereka bekerja. Komitmen Organisasi yang tinggi akan membuat manajer bekerja sebaik mungkin. Namun kemungkinan adanya keinginan manajer untuk bekerja di lembaga lain yang lebih baik akan membuat Komitmen Organisasi menjadi rendah sehingga Kinerja Manajerial akan semakin menurun.

Budgetary Goal Characteristics yang diperkuat atau diperlemah dengan adanya Kecukupan Anggaran dan Komitmen Organisasi akan memberikan pengaruh terhadap Kinerja Manajerial dalam suatu organisasi. Hal tersebut didukung oleh penelitian Yunita (2009) yang menunjukkan hasil bahwa partisipasi penyusunan anggaran berpengaruh positif terhadap Kinerja Manajerial yang diperkuat oleh Kecukupan Anggaran. Penelitian Siti Khotimah (2011) juga menunjukkan bahwa Komitmen Organisasi memperkuat hubungan antara karakteristik tujuan anggaran dengan Kinerja Manajerial Satuan Kerja Perangkat Daerah (SKPD) Kabupaten Blora. Berdasarkan uraian di atas maka penulis tertarik untuk meneliti tentang "Pengaruh Budgetary Goal Characteristics terhadap Kinerja Manajerial dengan
Kecukupan Anggaran dan Komitmen Organisasi sebagai Variabel Pemoderasi pada Universitas Negeri Yogyakarta “.

\section{METODE PENELITIAN}

\section{Jenis Penelitian}

Penelitian ini merupakan jenis penelitian kausal komparatif dengan pendekatan kuantitatif.

\section{Waktu dan Tempat Penelitian}

Penelitian ini dilaksanakan di Universitas Negeri Yogyakarta pada bagian perencanaan rektorat dan masing-masing fakultas. Waktu dari penelitian ini dilaksanakan pada bulan September 2015 hingga Maret 2016, sedangkan pelaksanaan pengambilan data dilakukan pada bulan Januari-Februari 2016.

\section{Target/Subjek Penelitian}

Populasi dalam penelitian ini adalah pejabat di lingkungan Universitas Negeri Yogyakarta yang berkedudukan sebagai kepala atau manajer serta terlibat aktif dalam penyusunan anggaran dan memiliki pengalaman kerja minimal dua tahun. Populasi dalam penelitian ini berjumlah 117 orang.

Adapun populasi tersebut yaitu kepala bagian perencanaan rektorat dan kepala sub bagian keuangan dan akuntansi, ketua jurusan, serta ketua program studi dari masing-masing fakultas di Universitas Yogyakarta. Fakultas tersebut terdiri dari Fakultas Ilmu Pendidikan, Fakultas Bahasa 


\section{JURNAL NOMINAL / VOLUME V NOMOR 1 / TAHUN 2016}

dan Seni, Fakultas Matematika dan Ilmu Pengetahuan Alam, Fakultas Ilmu Sosial, Fakultas Teknik, Fakultas Ilmu Keolahragaan, Fakultas Ekonomi, dan Program Pascasarjana Universtitas Negeri Yogyakarta.

\section{Prosedur}

Teknik pengumpulan data dalam penelitian ini dilakukan melalui survei dengan menggunakan angket atau kuesioner. Pengumpulan data dilakukan melalui dua metode, yaitu metode distribusi langsung dan metode email atau mail survey. Metode distribusi langsung dilakukan dengan cara mendatangi responden secara langsung ke lokasi penelitian dan menyebarkan kuesioner. Metode kedua yaitu metode email atau mail survey yang dilakukan dengan cara mengirimkan kuesioner kepada responden melalui alamat email.

Data, Instrumen, dan Teknik Analisis

\section{Data}

\section{Data dan Instrumen}

Data penelitian ini adalah data primer. Pengumpulan data dilakukan dengan menggunakan kuesioner. Kuesioner yang dipakai merupakan bentuk kuesioner tertutup yaitu kuesioner yang sudah disediakan jawaban dan responden tinggal memilih jawaban yang tersedia. Penyebaran kuesioner dilakukan dengan dua metode, yaitu metode distribusi langsung dan metode email atau mail survey. Metode distribusi langsung dilakukan dengan cara mendatangi responden secara langsung ke lokasi penelitian dan menyerahkan kuesioner. Bagi responden yang tidak ada di tempat maka kuesioner dititipkan kepada pihak yang bersedia menerima kuesioner. Penyebaran kuesioner pada Program Pascasarjana dikoordinasi oleh bagian umum dan perlengkapan sehingga peneliti tidak mendatangi responden pada Program Pascasarjana secara langsung. Pengambilan kuesioner dengan metode ini dilakukan sesuai perjanjian dengan responden. Metode kedua yaitu metode email atau mail survey dilakukan dengan cara mengirimkan kuesioner kepada responden melalui alamat email. Kuesioner yang disebar melalui email dilakukan pengecekan setiap hari untuk melihat tanggapan dari responden.

Masing-masing variabel diukur menggunakan instrumen penelitian yang diadopsi dari penelitian sebelumnya dengan dilakukan beberapa penyesuaian. Indikator yang digunakan untuk variabel Kinerja Manajerial yaitu perencanaan, pengorganisasian, pengarahan, dan pengawasan.

Budgetary

Goal

Characteristics menggunakan indikator partisipasi anggaran, kejelasan sasaran anggaran, evaluasi anggaran, umpan balik anggaran, dan kesulitan anggaran. Krcukupsn anggaran menggunakan indikator ketersediaan anggaran dan 


\section{JURNAL NOMINAL / VOLUME V NOMOR 1 / TAHUN 2016}

ketersediaan informasi, sedangkan Komitmen Organisasi menggunakan indikator kesetiaan dan kebanggaan, keterlibatan, serta keyakinan, penerimaan nilai, dan tujuan organisasi Teknik skala pengukuran menggunakan skala pengukuran Likert dengan modifikasi dengan skala 1 sampai 4 yaitu dari SS, S, TS, dan STS.

\section{Teknik Analisis Data}

Kuesioner yang nantinya akan disebarkan kepada responden harus diuji terlebih dahulu validitas dan reliabilitasnya. Uji coba instrumen dilakukan kepada 30 responden di luar populasi. Uji coba instrumen akan dilakukan di Dinas Sosial, Tenaga Kerja dan Transmigrasi Kota Yogyakarta. Setelah diperoleh data penelitian, dilakukan uji prasyarat analisis yang meliputi uji normalitas dan uji linieritas dan uji asumsi klasik yang meliputi uji multikolinearitas dan uji heteroskedastisitas. Metode analisis data yang digunakan adalah analisis regresi linier sederhana dan analisis regresi linier moderasi.

Pengambilan data secara primer dilakukan dengan menggunakan kuesioner, maka digunakan pengujian kualitas data dengan uji validitas dan reliabilitas. Uji validitas dan reliabilias menggunakan uji terpakai yaitu data yang digunakan untuk uji coba instrumen adalah data yang diperoleh

dengan sekali uji coba dan sekaligus digunakan sebagai data dalam penelitian. Dengan menggunakan uji coba terpakai maka item pernyataan yang dinyatakan valid langsung digunakan untuk uji hipotesis. Setelah diperoleh data penelitian, dilakukan uji statistik deskriptif, uji prasyarat analis yang terdiri dari uji linearitas dan uji asumsi klasik. Uji hipotesis dilakukan dengan menggunakan uji regresi linier sederhana dan Moderating Regression Analysis (MRA).

\section{HASIL PENELITIAN DAN PEM-}

\section{BAHASAN}

Data yang digunakan adalah data primer hasil kuesioner yang disebarkan kepada Kepala Bagian Perancanaan, Kepala Sub Bagian Keuangan dan Akuntansi, Ketua Jurusan, serta Ketua Program Studi Universitas Negeri Yogyakarta. Kuesioner yang disebarkan sebanyak 117 buah kuesioner dan yang dapat digunakan sebanyak 76 nuah kuesioner.

\section{Identitas Responden Penelitian}

Tabel 1. Jenis Kelamin Responden

Jenis Frequenc Percent

\begin{tabular}{ccc} 
Kelamin & $\boldsymbol{y}$ & \\
\hline Pria & 58 & $76,32 \%$ \\
\hline Wanita & 18 & $23,68 \%$ \\
\hline Total & 76 & $100,00 \%$ \\
& & \\
\hline \multicolumn{2}{l}{ Sumber: data } & \\
\hline
\end{tabular}


JURNAL NOMINAL / VOLUME V NOMOR 1 / TAHUN 2016

Tabel 2. Usia Responden

\begin{tabular}{|c|c|c|}
\hline Usia & Frequency & Percent \\
\hline$<25$ tahun & 0 & $0,00 \%$ \\
\hline $\begin{array}{l}25-35 \\
\text { tahun }\end{array}$ & 4 & $5,26 \%$ \\
\hline $\begin{array}{l}36-45 \\
\text { tahun }\end{array}$ & 28 & $36,84 \%$ \\
\hline $\begin{array}{l}46-55 \\
\text { tahun }\end{array}$ & 24 & $31,58 \%$ \\
\hline$>55$ tahun & 20 & $26,32 \%$ \\
\hline Total & 76 & $100 \%$ \\
\hline
\end{tabular}

Sumber: data primer diolah, 2016

Tabel 3. Jabatan di Organisasi Responden

\begin{tabular}{ccc}
\hline $\begin{array}{c}\text { Jabatan di } \\
\text { Organisasi }\end{array}$ & Frequency & Percent \\
Kabag & 1 & $1,32 \%$ \\
Perencanaan & & \\
\hline Kajur & 33 & $43,42 \%$ \\
\hline Kaprodi & 32 & $42,10 \%$ \\
\hline Kasubag & 7 & $9,21 \%$ \\
Keuangan & & \\
dan & & \\
Akuntansi & & $3,95 \%$ \\
\hline Lainnya & 3 & $100,00 \%$
\end{tabular}

Sumber: data primer diolah, 2016

Tabel 4. Lama Kerja Responden

\begin{tabular}{ccc}
\hline Lama Kerja & Frequency & Percent \\
\hline$<5$ tahun & 5 & $6,58 \%$ \\
\hline 5-10 tahun & 8 & $10,53 \%$ \\
\hline
\end{tabular}

\begin{tabular}{|c|c|c|}
\hline 11-15 tahun & 21 & $27,63 \%$ \\
\hline 16-20 tahun & 5 & $6,58 \%$ \\
\hline$>20$ tahun & 37 & $48,68 \%$ \\
\hline Total & 76 & $100,00 \%$ \\
\hline \multicolumn{3}{|c|}{ Sumber: data primer diolah, 2016} \\
\hline \multicolumn{3}{|c|}{ Tabel 5. Pendidikan Terakhir Responden } \\
\hline Pendidikan & Frequency & Percent \\
\hline \multicolumn{3}{|l|}{ Terakhir } \\
\hline D3 & 0 & $0,00 \%$ \\
\hline S1 & 3 & $3,95 \%$ \\
\hline $\mathbf{S 2}$ & 33 & $43,42 \%$ \\
\hline $\mathbf{S 3}$ & 40 & $52,63 \%$ \\
\hline Total & 76 & $100,00 \%$ \\
\hline
\end{tabular}

Sumber: data primer diolah, 2016

Tabel 6. Bagian/Fakultas Responden

Bagian/Fakultas Frequency Percent

Bagian $11,32 \%$

Perencanaan

$\begin{array}{lll}\text { Subag } & 7 & 9,21 \%\end{array}$

Keuangang dan

Akuntansi

\begin{tabular}{ccc}
\hline FIP & 8 & $10,52 \%$ \\
\hline FMIPA & 8 & $10,52 \%$ \\
\hline FBS & 8 & $10,52 \%$ \\
\hline FIK & 3 & $3,95 \%$ \\
\hline FT & 14 & $18,42 \%$ \\
\hline FIS & 7 & $9,21 \%$ \\
\hline FE & 6 & $7,91 \%$ \\
\hline PPs & 14 & $18,42 \%$ \\
\hline Total & 76 & $100,00 \%$
\end{tabular}

Sumber: data primer diolah, 2016 
Analisis Data

Tabel 7. Uji Linieritas

\begin{tabular}{lccc}
\hline $\begin{array}{c}\text { Hubungan } \\
\text { Variabel }\end{array}$ & $\begin{array}{c}\text { F } \\
\text { Hitung }\end{array}$ & $\begin{array}{c}\text { Linea } \\
\text { rity }\end{array}$ & $\begin{array}{c}\text { Ketera } \\
\text { ngan }\end{array}$ \\
\hline X terhadap & 28,723 & 0,000 & Linear \\
Y & & & \\
\hline
\end{tabular}

Sumber: Data primer yang diolah

Hasil uji linieritas menunjukkan bahwa Linearity memiliki nilai signifikansi kurang dari 0,05. Dengan demikian, hubungan antara variabel Budgetary Goal Characteristics dengan Kinerja Manajerial adalah linier.

Tabel 8. Uji Multikolinearitas

\begin{tabular}{ccccc}
\hline Kore & Vari & \multicolumn{2}{c}{ Perhitungan } & Keteran \\
\cline { 3 - 4 } lasi & abel & Toler & VIF & gan \\
& \multicolumn{4}{c}{ ance } \\
X - & $\mathrm{X}$ & 0,993 & 1,007 & Tidak \\
$\mathbf{Z}_{1}$ & $\mathrm{Z}_{1}$ & 0,990 & 1,010 & terjadi \\
& $\mathrm{XZ}_{1}$ & 0,985 & 1,015 & Multikoli \\
& & & & nearitas \\
\hline $\mathbf{X}$ - & $\mathrm{X}$ & 0,861 & 1,161 & Tidak \\
$\mathbf{Z}_{2}$ & $\mathrm{Z}_{2}$ & 0,788 & 1,268 & terjadi \\
& $\mathrm{XZ}_{2}$ & 0,909 & 1,100 & Multikoli \\
& & & & nearitas \\
\hline $\mathbf{X}^{n}-$ & $\mathrm{X}$ & 0,828 & 1,208 & Tidak \\
$\mathbf{Z}_{1}$ & $\mathrm{Z}_{1}$ & 0,682 & 1,467 & terjadi \\
dan & $\mathrm{Z}_{2}$ & 0,638 & 1,567 & Multikoli \\
$\mathbf{Z}_{2}$ & $\mathrm{XZ}_{1}$ & 0,667 & 1,500 & nearitas \\
& $\mathrm{Z}_{2}$ & & & \\
& & & &
\end{tabular}

Sumber: data primer diolah, 2016
Berdasarkan tabel tersebut menunjukkan bahwa menunjukkan bahwa semua variabel bebas mempunyai nilai tolerance $\geq 0,10$ dan nilai $\mathrm{VIF} \leq 10$ sehingga tidak terjadi multikolinearitas.

Tabel 9. Uji Heteroskedastisitas

Variabel Signifi Keterangan kansi

\begin{tabular}{lll}
\hline Budgetary Goal & 0,191 & $\begin{array}{l}\text { Tidak terjadi } \\
\text { heteroskedast } \\
\text { isitas }\end{array}$ \\
\hline Kecukupan & 0,174 & Tidak terjadi \\
Anggaran & & $\begin{array}{l}\text { heteroskedast } \\
\text { isitas }\end{array}$ \\
\hline Komitmen & 0,086 & Tidak terjadi \\
Organisasi & & heteroskedast \\
& & isitas
\end{tabular}

Sumber: data primer diolah, 2016

Berdasarkan tabel di atas menunjukkan bahwa seluruh variabel bebas mempunyai nilai probabilitas signifikansi lebih besar dari 0,05. Dengan demikian, hal ini dapat disimpulkan bahwa tidak terjadi heteroskedastisitas dalam model regresi

\section{Hasil Uji Hipotesis}

$\mathrm{H}_{1}$ : Budgetary goal characteristics berpengaruh positif terhadap Kinerja Manajerial pada Universitas Negeri Yogyakarta. 


\section{JURNAL NOMINAL / VOLUME V NOMOR 1 / TAHUN 2016}

.Tabel 10. Rangkuman Hasil Uji Hipotesis 1

\begin{tabular}{|c|c|c|c|}
\hline Variabel & $\begin{array}{l}\text { Koefisie } \\
\text { n } \\
\text { regresi }\end{array}$ & $\begin{array}{c}\mathbf{t}_{\text {hitun }} \\
\mathrm{g}\end{array}$ & Sig \\
\hline Konstanta & 1,779 & & \\
\hline Budgetary & 0,481 & 7,32 & 0,00 \\
\hline Goal & & 1 & 0 \\
\hline $\begin{array}{l}\text { Characteristic } \\
S\end{array}$ & & & \\
\hline $\mathrm{R} \quad: \mathbf{0 , 5 0 9}$ & & & \\
\hline
\end{tabular}

Sumber: Data primer yang diolah

Berdasarkan tabel di atas dapat dilihat bahwa nilai konstanta sebesar 1,779. Nilai koefisien Budgetary Goal Characteristics sebesar 0,481 dengan signifikansi 0,000. Dengan demikian, maka arah model regresi tersebut adalah positif. Hal ini juga dapat dilihat dari nilai korelasi regresi $(\mathrm{R})$ yang bernilai positif antara Budgetary Goal Characteristics dan Kinerja Manajerial yaitu sebesar 0,504. Oleh karena itu, semakin tinggi Budgetary Goal Characteristics maka akan semakin tinggi pula Kinerja Manajerial. Nilai koefisien determinasi $\mathrm{R}$ Square $\left(\mathrm{R}^{2}\right)$ sebesar 0,254. Hal tersebut menunjukkan bahwa sebesar 25,4\% Kinerja Manajerial di Universitas Negeri Yogyakarta dipengaruhi oleh Budgetary Goal Characteristics, sedangkan sisanya sebesar 74,6\% dipengaruhi oleh variabel lain di luar penelitian ini.
Pada hasil pengujian analisis regresi linear sederhana antara Budgetary Goal Characteristics dengan Kinerja Manajerial diperoleh $\mathrm{t}$ hitung lebih besar daripada $\mathrm{t}$ tabel yaitu thitung sebesar 5,018 dan t tabel sebesar 1,9917. Hasil dari uji t untuk variabel Budgetary Goal Characteristics menghasilkan nilai signifikansi 0,000, dimana nilai tersebut lebih kecil dari 0,05. Berdasarkan hasil yang diperoleh pada pengujian regresi linear sederhana ini, maka dapat disimpulkan bahwa Budgetary Goal Characteristics berpengaruh terhadap Kinerja Manajerial pada Universitas Negeri Yogyakarta. Dengan demikian, maka hipotesis pertama diterima.

Hasil penelitian ini mendukung hasil penelitian Siti Khotimah (2011) dengan judul "Pengaruh Karakteristik Tujuan Anggaran terhadap Kinerja Manajerial pada Satuan Kerja Perangkat Daerah (SKPD) di Kabupaten Blora dengan Komitmen Organisasi sebagai Variabel Moderating". Hasil penelitian tersebut menunjukkan bahwa Karakteristik Tujuan Anggaran berpengaruh signifikan terhadap Kinerja Manajerial di Satuan Kerja Perangkat Daerah (SKPD) di Kabupaten Blora.

Dari jawaban kuesioner yang diperoleh, distribusi kecenderungan variabel Budgetary Goal Characteristics sebanyak 63,16\% dan variabel Kinerja Manajerial sebanyak $51,32 \%$ berada posisi sedang. Berdasarkan hasil rekap data penelitian diperoleh nilai 


\section{JURNAL NOMINAL / VOLUME V NOMOR 1 / TAHUN 2016}

tertinggi variabel Budgetary Goal Characteristics berada pada indikator partisipasi anggaran yaitu terkait dengan tingkat keseringan manajer meminta pendapat bawahan dalam penentuan tujuan anggaran.

$\mathrm{H}_{2}$ : Kecukupan Anggaran memperkuat pengaruh positif Budgetary Goal Characteristics terhadap Kinerja Manajerial pada Universitas Negeri Yogyakarta.

Tabel 12. Rangkuman Hasil Uji Hipotesis 2

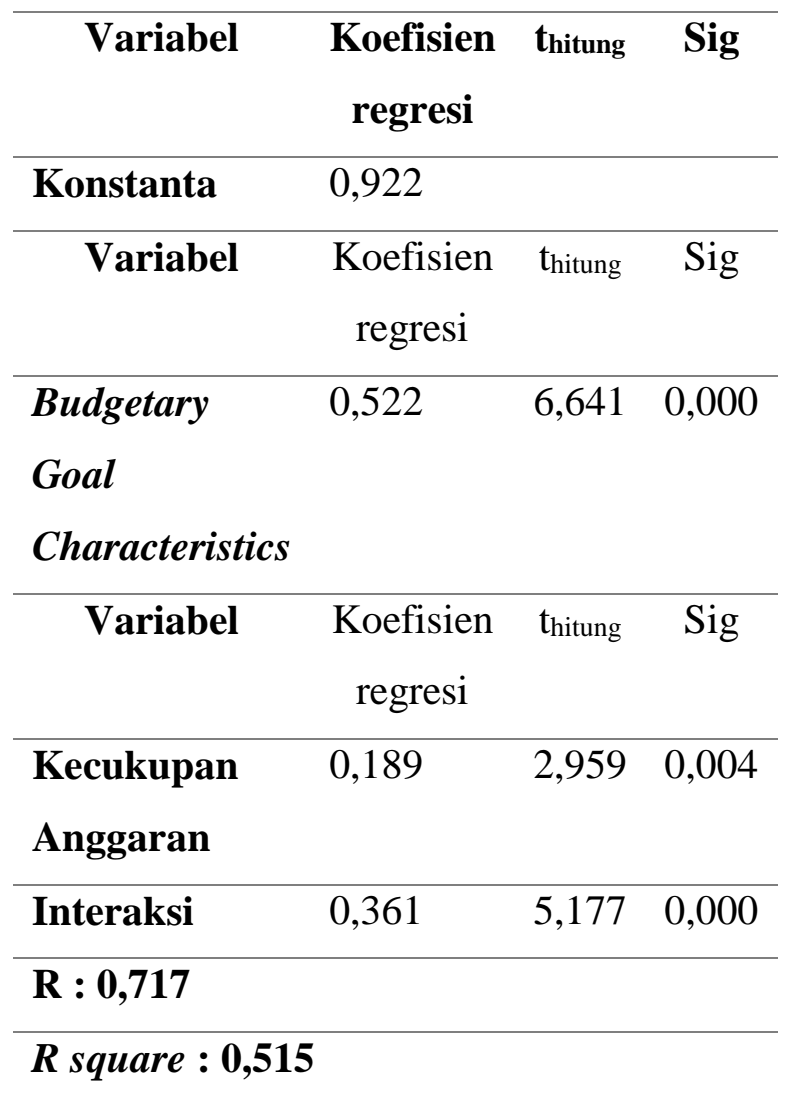

Sumber : data primer diolah, 2016

Berdasarkan tabel di atas, diketahui bahwa nilai konstanta sebesar 0,922. Budgetary Goal Characteristics mempunyai nilai koefisien 0,522 dengan signifikansi
0,000 dan $\mathrm{t}$ hitung sebesar 6,641. Kecukupan Anggaran mempunyai nilai koefisien 0,189 dengan signifikansi 0,004 dan t hitung sebesar 2,959. Interaksi antar kedua variabel tersebut menghasilkan nilai koefisien 0,361 dengan signifikansi 0,000 dan $\mathrm{t}$ hitung 5,177. Hasil tersebut menunjukkan adanya pengaruh positif sehingga semakin tinggi Budgetary Goal Characteristics dan Kecukupan Anggaran semakin tinggi pula Kinerja Manajerial pada Universitas Negeri Yogyakarta. Nilai $R^{2}$ sebesar 0,515 menunjukkan bahwa sebesar 51,5\% Kinerja Manajerial di Universitas Negeri Yogyakarta dipengaruhi oleh Budgetary Goal Characteristics dan Kecukupan Anggaran sedangkan sisanya sebesar 48,5\% dipengaruhi oleh variabel lain di luar penelitian ini.

Pengujian hipotesis 2 menunjukkan bahwa interaksi antara variabel $\mathrm{X}$ dan $\mathrm{Z}_{1}$ mempunyai pengaruh yang positif terhadap Y serta diperoleh nilai signifikansi $<0,05$. Besarnya $t$ hitung $>\mathrm{t}$ tabel yaitu 5,177>1,9917. Berdasarkan hasil tersebut maka hipotesis 2 diterima.

Hasil penelitian tersebut mendukung hasil penelitian Yunita (2009) dengan judul "Pengaruh Partisipasi Penyusunan Anggaran terhadap Kinerja Manajerial: Komitmen Organisasi dan Kecukupan Anggaran sebagai Variabel Kontijen (Studi Kasus pada Universitas Dian Nuswantoro Semarang)". Penelitian tersebut 


\section{JURNAL NOMINAL / VOLUME V NOMOR 1 / TAHUN 2016}

menunjukkan hasil bahwa partisipasi penyusunan anggaran berpengaruh positif terhadap Kinerja Manajerial dengan diperkuat Kecukupan Anggaran sebagai variabel moderating.

Berdasarkan data deskriptif menunjukkan bahwa Kecukupan Anggaran di Universitas Negeri Yogyakarta cukup tinggi, sebagian besar jawaban responden berada pada skala 3 dan 4. Dari hasil jawaban kuesioner dapat diketahui bahwa nilai paling tinggi berada pada item pernyataan terkait adanya informasi mengenai Kecukupan Anggaran. Manajer yang memiliki informasi Kecukupan Anggaran lebih termotivasi untuk mencapai target anggaran dan bekerja lebih baik. Dengan adanya Kecukupan Anggaran dan ketersediaan informasi yang memadai, manajer dapat mencapai tujuan dari anggaran yang telah ditetapkan sehingga dapat meningkatkan Kinerja Manajerialnya.

$\mathrm{H}_{3}$ : Komitmen Organisasi memperkuat pengaruh positif Budgetary Goal Characteristics terhadap Kinerja Manajerial pada Universitas Negeri Yogyakarta.

Tabel 13. Rangkuman Hasil Uji Hipotesis 3

\begin{tabular}{llll}
\hline \multicolumn{1}{c}{ Variabel } & $\begin{array}{c}\text { Koefisien } \\
\text { regresi }\end{array}$ & thitung & Sig \\
& 1,506 & & \\
\hline Konstanta & & & \\
\hline $\begin{array}{l}\text { Budgetary } \\
\text { Goal }\end{array}$ & 0,388 & 3,891 & 0,000 \\
& & & \\
\end{tabular}

Characteristics

Komitmen $\quad 0,301 \quad 2,378 \quad 0,020$

Organisasi

\begin{tabular}{llll}
\hline Interaksi & 0,063 & 0,546 & 0,587
\end{tabular}

R : 0,569

R square : 0,323

Sumber : data primer diolah, 2016

Berdasarkan tabel di atas, diketahui bahwa nilai konstanta sebesar 1,506. Budgetary Goal Characteristics mempunyai nilai koefisien 0,388 dengan signifikansi 0,000 dan t hitung sebesar 3,891. Komitmen Organisai mempunyai nilai koefisien 0,301 dengan signifikansi 0,020 dan $\mathrm{t}$ hitung sebesar 2,378. Interaksi antar kedua variabel tersebut menghasilkan nilai koefisien 0,063 dengan signifikansi 0,587 dan $\mathrm{t}$ hitung 0,546. Hasil tersebut menunjukkan adanya pengaruh positif sehingga semakin tinggi Budgetary Goal Characteristics dan Komitmen Organisasi semakin tinggi pula Kinerja Manajerial pada Universitas Negeri Yogyakarta. Nilai $\mathrm{R}^{2}$ sebesar 0,323 menunjukkan bahwa sebesar 32,2\% Kinerja Manajerial di Universitas Negeri Yogyakarta dipengaruhi oleh Budgetary Goal Characteristics dan Kecukupan Anggaran sedangkan sisanya sebesar 67,8\% dipengaruhi oleh variabel lain di luar penelitian ini.

Pengujian hipotesis 3 menunjukkan bahwa interaksi antara variabel $\mathrm{X}$ dan $\mathrm{Z}_{2}$ 


\section{JURNAL NOMINAL / VOLUME V NOMOR 1 / TAHUN 2016}

mempunyai pengaruh yang positif terhadap $\mathrm{Y}$, namun nilai signifikansi yang diperoleh $>0,05$ yaitu 0,587 . Besarnya t hitung $<\mathrm{t}$ tabel yaitu 0,546>1,9917. Berdasarkan hasil tersebut maka hipotesis 3 ditolak.

Hasil penelitian ini mendukung hasil dari penelitian Ratnawati Kurnia (2010) dengan judul "Pengaruh Budgetary Goal Characteristics terhadap Kinerja Manajerial dengan Budaya Paternalistik dan Komitmen Organisasi sebagai Moderating Variabel”. Hasil penelitian tersebut menunjukkan bahwa kesesuaian antara kelima komponen Budgetary Goal Characteristics dan Komitmen Organisasi tidak meningkatkan Kinerja Manajerial.

Berdasarkan data yang diperoleh dari skor jawaban kuesioner, distribusi frekuensi kecenderungan variabel Komitmen Organisasi berada pada posisi yang rendah. Nilai terendah berada pada item pernyataan terkait kesamaan sistem nilai (budaya) pada organisasi. Sebagian besar responden merasa bahwa sistem nilai (budaya) nya tidak sama dengan sistem nilai (budaya) organisasi. Responden pada penelitian ini semuanya adalah Pegawai Negeri Sipil (PNS). Keberlangsungan karir untuk bekerja terutama di Universitas Negeri Yogyakarta sudah pasti terjamin. Selain itu, dengan ada atau tidaknya peningkatan kinerja, pegawai akan tetap memperoleh insentif, sehingga Komitmen Organisasi tidak mempengaruhi karirnya. Dengan demikian maka Komitmen

Organisasi tidak berpengaruh terhadap Kinerja Manajerial.

$\mathrm{H}_{4}$ : Kecukupan Anggaran dan Komitmen Organisasi secara bersama-sama memperkuat pengaruh positif Budgetary Goal Characteristics terhadap Kinerja Manajerial pada Universitas Negeri Yogyakarta.

Tabel 14. Rangkuman Hasil Uji Hipotesis 4

\begin{tabular}{ccc}
\hline Variabel & $\begin{array}{c}\text { Koefisien } \\
\text { regresi }\end{array}$ & \\
&
\end{tabular}

Konstanta $\quad 0,595$

$\begin{array}{llll}\text { Budgetary } & 0,448 & 4,682 & 0,000\end{array}$

Goal

Characteristics

\begin{tabular}{llll}
\hline Kecukupan & 0,275 & 3,205 & 0,002
\end{tabular}

Anggaran

$\begin{array}{llll}\text { Komitmen } & 0,116 & 0,875 & 0,385 \\ \text { Organisasi } & & & \end{array}$

\begin{tabular}{lll}
\hline Interaksi & 0,273 & $2,151 \quad 0,035$ \\
\hline F hitung & 12,278, Sig. $=0,000$
\end{tabular}

R : 0,639

R square : 0,409

Sumber : data primer diolah, 2016

Berdasarkan tabel di atas, diketahui bahwa nilai konstanta sebesar 0,595. Budgetary Goal Characteristics mempunyai nilai koefisien 0,448 dengan signifikansi 0,000 dan $\mathrm{t}$ hitung sebesar 4,682. Kecukupan Anggaran mempunyai nilai 


\section{JURNAL NOMINAL / VOLUME V NOMOR 1 / TAHUN 2016}

koefisien 0,275 dengan signifikansi 0,002 dan $\mathrm{t}$ hitung sebesar 3,205. Komitmen Organisasi mempunyai nilai koefisien 0,116 dengan signifikansi 0,385 dan $\mathrm{t}$ hitung sebesar 0,875. Interaksi antar kedua variabel tersebut menghasilkan nilai koefisien 0,273 dengan signifikansi 0,035 dan $\mathrm{t}$ hitung 2,151. Hasil tersebut menunjukkan adanya pengaruh positif sehingga semakin tinggi Budgetary Goal Characteristics, Kecukupan Anggaran, dan Komitmen Organisasi semakin tinggi pula Kinerja Manajerial pada Universitas Negeri Yogyakarta. Nilai $R^{2}$ sebesar 0,409 menunjukkan bahwa sebesar 40,9\% Kinerja Manajerial di Universitas Negeri Yogyakarta dipengaruhi oleh Budgetary Goal Characteristics dan Kecukupan Anggaran sedangkan sisanya sebesar 59,1\% dipengaruhi oleh variabel lain di luar penelitian ini.

Pengujian hipotesis 4 menunjukkan bahwa interaksi antara variabel $\mathrm{X}, \mathrm{Z}_{1}$ dan $\mathrm{Z}_{2}$ mempunyai pengaruh yang positif terhadap $\mathrm{Y}$, nilai signifikansi yang diperoleh $>0,05$ yaitu 0,035 . Besarnya $t$ hitung $>t$ tabel yaitu 2,151>1,9917. Berdasarkan hasil tersebut maka hipotesis 4 diterima.

Hasil penelitian ini mendukung hasil penelitian dari Yunita (2009) dan Siti Khotimah (2011). Penelitian Yunita (2009) menunjukkan hasil bahwa partisipasi anggaran berpengaruh positif terhadap Kinerja Manajerial dengan Kecukupan Anggaran sebagai variabel moderating, sedangkan penelitian Siti Khotimah (2011) menunjukkan hasil bahwa interaksi antara Komitmen Organisasi dan karakteristik tujuan anggaran secara signifikan mempengaruhi Kinerja Manajerial.

Berdasarkan hasil dari jawaban kuesioner diketahui bahwa kecenderungan variabel Kinerja Manajerial sebanyak $51,32 \%$ berada pada posisi sedang dan $46,05 \%$ berada pada posisi tinggi. Hal tersebut menunjukkan bahwa dari hasil penelitian ini tingkat Kinerja Manajerial di Universitas Negeri Yogyakarta sudah baik. Hal tersebut juga diperkuat dari hasil jawaban responden diperoleh skor yang tinggi pada setiap item pernyataan. Ketercapaian dari Budgetary Goal Characteristics yang diperkuat oleh Kecukupan Anggaran dan Komitmen Organisasi semakin meningkatkan Kinerja Manajerial di Universitas Negeri Yogyakarta.

\section{SIMPULAN DAN SARAN}

\section{Simpulan}

a. Pengujian yang dilakukan memberikan hasil yang mendukung dan menerima hipotesis 1 yaitu Budgetary Goal Characteristics berpengaruh positif terhadap Kinerja Manajerial pada Universitas Negeri Yogyakarta. Hal ini ditunjukkan dengan nilai koefisien regresi $\mathrm{X}$ sebesar 0,481 dengan signifikansi 0,000. Nilai t hitung lebih 


\section{JURNAL NOMINAL / VOLUME V NOMOR 1 / TAHUN 2016}

besar daripada $\mathrm{t}$ tabel yaitu $\mathrm{t}$ hitung sebesar 5,018 dan t tabel sebesar 1,9917 serta nilai F sebesar 25,179 dengan signifikansi 0,000. Korelasi regresi (R) antara Budgetary Goal Characteristics terhadap Kinerja Manajerial bernilai positif yaitu 0,504 .

b. Pengujian yang dilakukan memberikan hasil yang mendukung dan menerima hipotesis 2 yaitu Kecukupan Anggaran memperkuat pengaruh positif Budgetary Goal Characteristics terhadap Kinerja Manajerial pada Universitas Negeri Yogyakarta. Hal ini ditujukkan dengan diperolehnya nilai koefsien interaksi $\mathrm{X}_{\mathrm{Z1}}$ $\left(\beta_{3}\right)$ sebesar 0,361 dengan $t$ hitung sebesar 5,177 dan signifikasi 0,000<0,05. Nilai F sebesar 25,463 dengan signifikansi 0,000 . Nilai koefisien dan korelasi regresi (R) sebesar 0,717 yang berarti menunjukkan adanya pengaruh positif.

c. Pengujian yang dilakukan memberikan hasil yang menolak hipotesis 3 yang menyatakan bahwa Komitmen Organisasi memperkuat pengaruh positif Budgetary Goal Characteristics terhadap Kinerja Manajerial pada Universitas Negeri Yogyakarta. Hal ini dibuktikan dengan diperolehnya nilai koefsien interaksi $\mathrm{XZ}_{2}$ $\left(\beta_{3}\right)$ sebesar 0,063 dengan t hitung lebih kecil daripada t tabel yaitu $0,546<1,9917$. Besarnya nilai $\mathrm{F}$ yaitu 11,469 dengan signifikansi 0,000. Signifikansi interaksi
$\mathrm{XZ}_{2}$ menunjukkan hasil yang tidak signifikan yaitu 0,587>0,05. Meskipun nilai koefisien dan nilai $\mathrm{R}$ menunjukkan adanya pengaruh positif yaitu 0,569 namun $\mathrm{H}_{1}$ tidak dapat diterima karena berdasarkan pengujian hipotesis menunjukkan hasil yang tidak signifikan serta $\mathrm{t}$ hitung lebih kecil dari $\mathrm{t}$ tabel.

d. Pengujian yang dilakukan memberikan hasil yang mendukung dan menerima hipotesis 4 yaitu Kecukupan Anggaran dan Komitmen Organisasi secara bersama-sama memperkuat pengaruh positif Budgetary Goal Characteristics terhadap Kinerja Manajerial pada Universitas Negeri Yogyakarta. Hal ini dibuktikan dengan diperolehnya nilai koefsien interaksi $\mathrm{XZ}_{1} \mathrm{Z}_{2}\left(\beta_{4}\right)$ sebesar 0,273 dengan $t$ hitung lebih besar daripada $t$ tabel yaitu $2,151>1,9917$ dan nilai $\mathrm{F}$ sebesar 12,278 dengan signifikansi 0,000 . Signifikansi interaksi $\mathrm{XZ}_{1} \mathrm{Z}_{2}$ menunjukkan hasil yang signifikan yaitu $0,035<0,05$. Nilai koefisien dan nilai $(\mathrm{R})$ sebesar 0,639 menunjukkan adanya pengaruh positif. Dengan demikian, maka semakin tinggi Budgetary Goal Characteristics, Kecukupan Anggaran, dan Komitmen Organisasi pada Universitas Negeri Yogyakarta maka semakin tinggi pula Kinerja Manajerialnya. 


\section{JURNAL NOMINAL / VOLUME V NOMOR 1 / TAHUN 2016}

\section{Saran}

a. Bagi Universitas Negeri Yogyakarta

1. Manajemen Universitas Negeri Yogyakarta hendaknya lebih meningkatkan pengawasan terhadap pelaksaan anggaran agar anggaran yang ada dapat memadai untuk mencapai tujuan dan perencanaan yang telah ditetapkan.

2. Bagi manajer tingkat atas di lingkungan Universitas Negeri Yogyakarta sebaiknya lebih banyak melibatkan manajer tingkat menengah dan bawah khususnya ketua jurusan dan ketua prodi dalam penetapan dan pelaksanaan anggaran. Adanya partisipasi yang tinggi akan meningkatkan Kinerja Manajerial karena manajer akan mengetahui mengenai kejelasan anggaran yang tersedia. Hasil pelaksanaan anggaran dapat digunakan sebagai dasar evaluasi dan umpan balik dalam penilaian kinerja manajer, sehingga perlu dilakukan evaluasi terhadap pelaksanaan anggaran secara rutin agar dapat diketahui efektivitas dan efisiensi dari anggaran serta diperoleh umpan balik guna memperbaiki dan meningkat Kinerja Manajerial. Penetapan anggaran juga perlu diberikan tingkat kesulitan tertentu karena dengan adanya tingkat kesulitan anggaran akan mendorong manajer untuk bekerja lebih keras sehingga hasil yang dicapai dapat meningkatkan kinerjanya.

3. Bagi semua manajer di Universitas Negeri Yogyakarta untuk lebih meningkatkan loyalitas dan penerimaan nilai-nilai dalam organisasi sehingga Komitmen Organisasi dapat meningkat. Apabila manajer memiliki Komitmen Organisasi yang tinggi maka Kinerja Manajerial akan meningkat.

b. Bagi Penelitian Selanjutnya

1. Pada penelitian selanjutnya sebaiknya jumlah populasi dan sampel ditambah dan diperluas sesuai dengan kategori tertentu sehingga data yang didapat lebih luas dan dapat membandingkan antara Universitas satu dengan Universitas yang lain.

2. Pada saat penyebaran kuesioner akan lebih baik jika peneliti menjelaskan variabel yang diajukan dalam item pernyataan kuesioner untuk menghindari adanya perbedaan persepsi antara responden dengan item pernyataan yang diajukan.

3. Apabila menggunakan Universitas sebagai tempat penelitian, maka sebaiknya dilakukan pada saat libur semester agar responden memiliki lebih banyak waktu luang untuk mengisi kuesioner serta menambah waktu penelitian. 


\section{DAFTAR PUSTAKA}

Allen, N.J., dan Meyer, J.P. (1990). "The Measurement and Attendents of Affective, Continuance and Normative Commitment to The Organizational. Journal of Occupational Psycologi”. Vol. 63 No. 1 Pp. 1-18.

Anthony, Robert N. dan Govindrajan, Vijay. (2011). Management Control System. Jakarta: Salemba Empat.

Arfan Ikhsan dan Muhammad Ishak. (2005). Akuntansi Keprilakuan. Jakarta: Salemba Empat.

Dewi, Aridayani Puspita. (2014). "Pengaruh Partisipasi Anggaran dan Komitmen Organisasi terhadap Kinerja Manjerial (Studi Kasus pada Universitas Widyatama Bandung)". Skripsi. Universitas Widyatama, Bandung.

Desy Lesmana. (2011). "Pengaruh Penganggaran Partisipatif, Sistem Pengukuran Kinerja dan Kompensasi Insentif terhadap Kinerja Manajerial Perguruan Tinggi Swasta di Palembang". Jurnal Ekonomi dan Informasi Akuntansi (Jenius) Vol. 1 No. 3 Hal. 238-252.

Didit Herlianto. (2011). Teknik Penyusunan Anggaran Operasional Perusahaan. Yogyakarta: Gosyen Publishing.

Eko Budi Santoso dan Tommi Adrian Hartanto. (2012). "Partisipasi Anggaran dan Kinerja Manajerial dengan Kecukupan Anggaran dan Job Relevant Information sebagai Variabel Intervening". JRAK. Vol. 8 Hal 19-33.

Welsch, Glenn A., Hiltong, Ronald W., dan Gordon, Paul N. (2000). Anggaran: Perencanaan dan Pengendalian Laba. Jakarta: Salemba Empat.

Guidio Giusti. (2013). "Pengaruh Partisipasi Anggaran terhadap Senjangan Anggaran dengan Budaya Organisasi sebagai Variabel Moderating (Studi Empiris pada SKPD-SKPD Kabupaten Jember)". Skripsi. Universitas Jember, Jawa Timur.

Griffin, Ricky W. (2004). Manajemen. Jakarta: Erlangga.

Hansen dan Mowen. (2012). Akuntansi Manajerial. Jakarta: Salemba Empat.

Husein Umar. (2011). Metode Penelitian untuk Skripsi dan Tesis Bisnis. Jakarta: PT Raja Grafindo Persada.

Ida Ayu M. dan I Ketut Sujana. (2008). "Pengaruh Pengaruh Budgetary Goal Characteristics terhadap Kinerja Manajerial pada Rumah Sakit Pemerintah di Kota Denpasar". Jurnal Akuntansi Universitas Udayana Bali.

Imam Ghozali. (2011). Aplikasi Analisis Multivariate dengan Program IBM SPSS. Semarang: Badan Penerbit Universitas Diponegoro.

Irham Fahmi. (2012). Manajemen Teori, Kasus, dan Solusi. Bandung: Alfabeta.

Ivancevich, John. (1976). "Effects of Goal Setting on Performance and Job Satisfaction". Journal of Applied Psychology. Pp 605-612.

Kenis, Izzettin. (1979). "Effects of Budgetary Goal Characteristics on Managerial Attitudes and Performance". The Accounting Review. Vol. 54 No. 24 (Oct, 1979) Pp 707-721.

Kreitner, Robert dan Kinicki, Angelo. (2003). Perilaku Organisasi. Jakarta: Salemba Empat.

Laporan Tahunan 2013 Universitas Negeri Yogyakarta.

Laporan Dies Natalis Ke-51 Universitas Negeri Yogyakarta 2015. 


\section{JURNAL NOMINAL / VOLUME V NOMOR 1 / TAHUN 2016}

Lie Liana. (2009). "Penggunaan MRA dengan SPSS untuk Menguji Pengaruh Variabel Moderating terhadap Hubungan antara Variabel Independen dan Variabel Dependen. Jurnal Teknologi Informasi DINAMIK. Vol. XIV No. 2 Hal. 90-97.

M. Nafarin. (2007). Penganggaran Perusahaan. Jakarta: Salemba Empat.

Mahoney, T.A. et.al. (1965). "The Job of Management, Industrial Relations" Vol. 2 Hal. 97-110.

Mowday, R., R. Steers dan L.Porter, (1979). "The Measurement of Organizational Commitment". Journal of Vocational Behavior. 14: 224-247.

Mulyadi. (2001). Akuntansi Manajemen. Yogyakarta: Sekolah Tinggi Ilmu Ekonomi.

Munandar. (2001). Pengkoordinasian Kerja Pengawasan Kerja. Yogyakarta: BPFE.

Nanda Hapsari A. R. (2010). "Pengaruh Partisipasi Penyusunan Anggaran terhadap Kinerja Manajerial dengan Komitmen Organisasi dan Locus of Control sebagai variabel Moderating”. Skripsi. Universitas Diponegoro, Semarang.

Nourin H. dan Parker R. J. (1998). "The Relationship Between Budget Participation and Job Performance: The Rule of Budget Adequacy and Organizational Commitment".

Ogiedu, Killian Osikhena dan Odia, James. Tanpa Tahun."Relationship between Budget Participation, Budget Procedural Fairness, Organisational Commitment and Managerial Performance". University of Benin. Hal 252-269.

Pangkalan Data Perguruan Tinggi. Diakses dari: www.dikti.go.id pada 5 Mei 2015.
Peraturan Pemerintah Republik Indonesia Nomor 17 tahun 2010 tentang Pengelolaan dan Penyelengaraan Pendidikan.

Profil Universitas Negeri Yogyakarata. Diakses dari: www.uny.ac.id pada 5 Mei 2015.

Ratnawati Kurnia. (2010). "Pengaruh Budgetary Goal Characteristics terhadap Kinerja Manajerial dengan Budaya Paternalistik dan Komitmen Organisasi sebagai Moderating Variabel". Jurnal Ultima Accounting. Vol. 2 No. 2 Hal 54-72.

Siti Khotimah. (2011). "Pengaruh Karakteristik Tujuan Anggaran terhadap Kinerja Manajerial pada Satuan Kerja Perangkat Daerah (SKPD) di Kabupaten Blora dengan Komitmen Organisasi sebagai Variabel Moderating". Skripsi. Universitas Negeri Semarang, Semarang.

Sri Rahayu dan Andry Arifian Rachman. (2013). Penyusunan Anggaran Perusahaan. Bandung: Graha Ilmu.

Steers, R. M. (1975). “Task Goal Attributes, Achievement, and Supervisory Performance, Organizational Behavior and Human Performance". Pp 392-403.

Stefani Lily Indarto dan Stephana Dyah Ayu. (2011). "Pengaruh Partisipasi dalam Penyusunan Anggaran terhadap Kinerja Manajerial Perusahaan melalui Kecukupan Anggaran, Komitmen Organisasi, Komitmen Tujuan Anggaran, dan Job Relevant Information (JRI)". Seri Kajian Ilmiah. Vol. 4 No. 1 Hal. 1-44.

Sugiyono. (2011). Metode Penelitian Kombinasi (Mixed Methods). Bandung: Alfabeta.

(2012). Statistika untuk Penelitian. Bandung: Alfabeta. 


\section{JURNAL NOMINAL / VOLUME V NOMOR 1 / TAHUN 2016}

(2014). Metode Penelitian Kuantitati Kualitatif dan $R \& D$. Bandung: Alfabeta.

Suharsimi Arikunto. (2010). Prosedur Penelitian Suatu Pendekatan. Jakarta: Rineka Cipta.

Sutrisno Hadi. (2004). Analisis Regresi. Yogyakarta: Andi Offset.

Syafrizal, Said Herry, dan Cut Aknawal. (2011). "Pengaruh Karakteristik Tujuan Anggaran terhadap Kinerja Manajerial dengan Komitmen Organisasim sebagai Variabel Moderating pada Pemerintah Kota Banda Aceh". Jurnal E-Mabis FEUnimal. Vol. 12 No. 2.

T, Hani Handoko. (2003). Manajemen. Yogyakarta: BPFE-Yogyakarta.

Velerie, LaMastro. (1999). "Commitment and Perceived Organizational Support. National Forum of Applied Educational". Research Journal. Vol. 12 No. 3 Hal.1-13.

Wangi W., Gede A.Y., dan Anantawikrama T.A. (2014). "Pengaruh Budgetary Goal Characteristics terhadap Kinerja Manajerial dengan Budaya Paternalistik dan Komitmen Organisasi sebagai Moderating Variabel (Studi Empiris pada DinasDinas Pemerintah Kabupaten Bandung)". E-Journal S1 Akuntansi Universitas Pendidikan Ganesha. Vol. 2 No. 1.

Widi Hariyanti. (2002). "Pengaruh Partisipasi Penyusunan Anggaran terhadap Kinerja Manajerial: Peran Kecukupan Anggaran dan Komitmen Organisasi sebagai Variabel Intervening". Tesis. Universitas Diponegoro, Semarang.

Yunita. (2009). "Pengaruh Partisipasi Penyusunan Anggaran terhadap
Kinerja Manajerial: Komitmen Organisasi dan Kecukupan Anggaran sebagai Variabel Kontijensi (Studi Kasus pada Universitas Dian Nuswantoro Semarang)". Tesis. Universitas Dian Nuswantoro, Semarang. 